\title{
Hamaca Paraguaya: luto e resistência no cinema latino-americano contemporâneo
}

\section{Hamaca Paraguaya: mourning and resistance in the Latin-American contemporary cinema}

Bárbara Xavier França

UFMG

Resumo: Como o filme paraguaio Hamaca Paraguaya (Paz Encina, 2006) cifra a história? O filme, o primeiro longa realizado no país desde 1978, apresenta um casal de velhos sentados em uma rede, reclamando das intempéries do dia e da ausência do filho, que partiu para uma guerra e possivelmente lá morreu. O presente trabalho toma aspectos da escritura fílmica como as repetições presentes nos diálogos entre os personagens, no posicionamento de câmera e nos padrões da montagem, bem como na utilização do extracampo e no desenvolvimento narrativo, buscando pensar a ideia de um tempo suspenso. A partir de então, discute como esse estado pode expressar uma relação com a memória de períodos traumáticos, como a guerra, resistindo ao luto e ao esquecimento. Por fim, coloca Hamaca em relação ao cinema latino-americano contemporâneo e aos "cinemas novos" que surgiram na região.

Palavras-chave: Hamaca Paraguaya; Paraguai; Cinema Latino-americano; Pausa; Luto e Melancolia

Abstract: How does Hamaca Paraguaya (Paz Encina, 2006) impart history? The Paraguayan film, first produced in the country since 1978, presents an old couple lying down in a hammock, complaining about life matters and the absence of their son, who has joined the army and has probably died in the battlefield. This present article takes aspects of filmic writing as repetition in the dialogues, camera positioning and composition patterns as well as the use of off-screen and narrative development aiming discuss the idea of a suspended time. 
Then, it deliberates how this state can speak of a relationship marked by the memory of traumatic periods, such as a war, resisting grief and oblivion. Finally, it relates Hamaca to the contemporary Latin America cinema and the "new cinemas" that emerged there.

Keywords: Hamaca Paraguaya; Paraguay; Latin-American Contemporary Cinema; Pause; Mourning and Melancholia

\section{Introdução}

Uma guerra, um filho ausente e uma espera incessante. Em Hamaca Paraguaya, filme lançado em 2006, a jovem diretora Paz Encina nos apresenta um ambiente em meio a uma mata fechada, cujo chão está coberto de folhas secas. Lá um casal de velhos escolherá, entre duas grandes árvores, amarrar sua rede. Desde o nascer do sol até o cair da noite eles permanecerão, sempre esperando o que, nas palavras de Cândida, nunca vem. Cândida é a mãe, que partilha a rede com Ramón, o pai, enquanto falam dos latidos da cadela, do calor insuportável, da chuva iminente, do filho que se foi e de uma guerra distante.

Assistir a Hamaca Paraguaya é uma experiência difícil. Os personagens estão posicionados a tal distância do espectador que quase não podemos identificar o que eles estão fazendo, que tipo de objeto estão manuseando, para onde ou o que estão olhando, bem como qual expressão ilumina seus rostos, ainda que seja possível notar o ato de descascar alguma coisa, de se abanar, de mover-se na rede. A câmera sempre parada e os longos planossequências nos submetem à contemplação daquilo que mal se pode ver. E o que ouvimos é repetitivo, fragmentado, até enigmático. As vozes estão sobrepostas às imagens e não são sincrônicas. Na banda sonora, aliás, há personagens não visíveis, cujas vozes constituem diálogos com Cândida e Ramón, através dos quais ficamos sabendo que o filho, em decorrência da tal guerra, se despede, e que, por causa dela, pode ter morrido. Além do mais, os diálogos, todos eles, são em guarani, segunda língua oficial do Paraguai, mas ainda estigmatizada, ligada à pobreza e à marginalidade, falada em sua maioria por habitantes da 
zona rural (ROMERO, 2012, p.312).

Os personagens são apreendidos em planos-sequências que criam um tempo dilatado e nos mergulham na duração concreta da realização de seus gestos, ou, mais radicalmente, na duração do "nada", da pura espera. O acontecimento que causou a ausência do filho transcorre em algum outro lugar bem longe dali, mas a morte está sempre à espreita, prestes a ser confirmada, mesmo que constantemente negada pelos pais.

Hamaca Paraguaya trabalha com diferentes temporalidades. Enquanto, durante os aproximadamente 77 minutos de filme, testemunhamos o que aparenta ser a passagem de um dia inteiro, os diálogos na banda sonora vêm do passado ou de um momento posterior à guerra. Não sabemos, no entanto, localizar exatamente esses diálogos em relação ao presente de Cândida e Ramón, enquanto nos temas abordados nas falas, nos posicionamentos de câmera, na montagem, predomina a repetição.

Tal "espera pura" - ou, para usar o termo que a autora Andrea Molfetta (2011) buscou em Deleuze para falar dos tempos mortos e do "não avançar" no cinema latino-americano, "pausa" -, nos levam a relacioná-la ao estado de melancolia e a uma resistência ao trabalho de luto, que não se permite realizar para não permitir, por sua vez, o esquecimento. No presente trabalho, acionamos os conceitos de luto e melancolia buscando pensá-los em uma perspectiva política e indagar a inserção do filme em um contexto histórico e social. Como Hamaca Paraguaya cifra a história ${ }^{1}$ ? Acreditamos que o filme realiza uma série de operações que permitem uma leitura da história paraguaia e também latino-americana a contrapelo, a partir da versão dos vencidos.

Para tanto, tomamos a última cena como principal ponto de partida para a reflexão, uma vez que, nela, os diálogos sobre a guerra, a ausência do filho e o esquecimento ganham mais desenvolvimento que em cenas anteriores, sem deixar, no entanto, de se manifestarem por meio das construções fragmentadas dos diálogos, presentes em toda a obra. Discutimos, então, o conceito de "pausa" com Molfetta (2011) e Deleuze (2007) e pensamos sua relação

\footnotetext{
$1 \quad$ Neste trabalho optamos por grafar "história" sempre com h minúsculo. Ao padronizar, assumimos que os diferentes sentidos do termo, que pode se referir à narração sistemática dos fatos passados que constituem a memória de um povo, ao enredo desenvolvido pela narrativa fílmica, à narração de vivências, dentre outros, são passíveis de identificação conforme o contexto em que a palavra é acionada.
} 
com um estado de trauma no filme. Passamos, então, para a reflexão sobre como o filme de Encina, na esteira de pesquisadores como Idelber Avelar (2003), Jaime Ginzburg (2012) e Jeanne Marie Gagnebin (2012), abarca os restos e opera uma resistência ao trabalho de luto, propondo pensar então como as escolhas da escritura fílmica operam uma resistência ao esquecimento e, por conseguinte, uma resistência política. Antes, no entanto, contextualizamos Hamaca Paraguaya dentro do cinema paraguaio e da trajetória de Paz Encina enquanto diretora. Enfim, como considerações finais, colocamos a obra em relação aos "cinemas novos" e ao cinema latino-americano contemporâneo, problematizando a categoria "neorrealismo cotidiano", elaborada pelo pesquisador equatoriano Galo Alfredo Torres (2011).

\section{Hamaca Paraguaya e cinema paraguaio}

Hamaca Paraguaya é o primeiro longa-metragem rodado em $35 \mathrm{~mm}$ no país desde 1978. O último, Cerro Corá, um épico dirigido por Guillermo Vera, é resultado do investimento da ditadura de Alfredo Stroessner para a realização de um grande projeto fílmico sobre a Guerra da Tríplice Aliança (1864-1870), contra Uruguai, Argentina e Brasil, também conhecida como Guerra do Paraguai ou Guerra Grande. De acordo com a pesquisadora Eva Romero (2012), o filme se dedica inteiramente a reforçar o discurso histórico a respeito de Francisco Solano López, ditador paraguaio à época, como o herói nacional. Segundo ela, da mesma forma como Solano López continuava a ser reverenciado mesmo com tantas mortes deixadas por seu regime, Stroessner também queria um lugar entre o panteão dos mártires paraguaios, daí a retomada deste evento. Um agradecimento ao "grande líder" de outrora pelo apoio à cultura do país aparece, inclusive, na introdução do filme que, conforme Paz Encina (2007), conta em seu casting com os filhos de López.

Quase trinta anos depois, Hamaca surge retomando outro conflito, a Guerra do Chaco (1932-1935). Segundo David Zook Jr. (1962), a luta contra a Bolívia, motivada pelo interesse no petróleo, se desenvolveu no chamado Chaco Boreal, zona situada ao norte do conjunto 
conhecido como Grand Chaco e caracterizada pela presença de um deserto árido, "onde o suco dos cactos substitui a água e os insetos chupadores de sangue fervem aos milhões" (ZOOK JR., p.21, 1962). A guerra é lembrada pelo feito heroico do Paraguai que, em desvantagem no poderio bélico e no número de soldados, vira o jogo e vence a disputa por um território tão inóspito e seco que a sede se tornara o pior inimigo, para os dois lados em guerra. Como dizia Augusto Roa Bastos, grande escritor e roteirista paraguaio, sobre a Guerra da Sede: seria vencedor aquele que conseguisse levar água às suas linhas de frente.

A vitória paraguaia fez o país entrar em um período de otimismo que, conforme Charles Arnade (1962), favoreceu a permanência do modelo político vigente e do ordenamento social característico da América Espanhola do século XVIII, marcado ainda pelo caudilhismo - não muito diferente de outros países latino-americanos. Paradoxalmente, se nos anos 1970, para exaltar a cultura nacional, o cinema aciona uma guerra que devastou quase metade da população do país e da qual o Paraguai saiu perdedor e humilhado, o filme de Encina se apropria da guerra vitoriosa para falar de seus mortos.

A diretora nasceu em Assunção em 1971 e antes do longa já havia realizado os curtas La siesta (1997), Los encantos del jazmín (1996), Hamaca Paraguaya (2000), homônimo, e Supe que estabas triste (2001). Ela se formou em cinema na Argentina e trabalhou com cineastas daquele país, Pablo Trapero e Lucrecia Martel. Em seu texto Arrastrando la tormenta (2008), Encina comenta que uma de suas motivações para levar a cabo o projeto de Hamaca era abordar ou retratar o silêncio presente tanto na história como no cinema paraguaios. "Até a data de hoje, somos o único país na América do Sul que não conta com um Instituto de Cinematografia; Equador tem um desde 18 de outubro de 2006 e, a partir de então, nós somos os únicos. Ou os últimos” (ENCINA, 2008, p.331-332) 2 .

John King (1994), no livro El carrete mágico: una historia del cine latinoamericano, atribui ao longo período de ditadura Stroessner, de 1954 a 1989, um dos motivos pela quase ausente produção cinematográfica no país, envolto em medo, tortura, prisão e repressão. "A comunidade cultural foi molestada e dividida: muitos viveram a solidão do exílio ou

\footnotetext{
2 No original: "A la fecha, somos el único país en América del Sur que no cuenta com un Instituto de Cinematografía; Ecuardor lo tiene desde el 18 de octubre de 2006 y desde ese momento, nos constituimos los únicos. O los últimos".
} 
permaneceram asfixiados no país. Alguns artistas produziram trabalhos notáveis nestas condições - os escritos de Roa Bastos são exemplares nesse sentido - mas no cinema o trabalho foi escasso e isolado" (KING, 1994, p.150) ${ }^{3}$.

De acordo com o autor, em meados dos anos 1960, surgiu um movimento de cinema independente liderado por cineastas como Carlos Saguier e Jesús Ruiz Nestosa, que produziram vários curtas sobre aspectos da cultura do país. Em 1969, Saguier teve a "audácia" de lançar El Pueblo, um documentário de 40 minutos sobre o cotidiano, a religião e a pobreza desta “"terra sem homens e homens sem terra', nas palavras de Roa Bastos” (KING, 1994, p.151) ${ }^{4}$. O feito foi reconhecido por uma revista de cinema peruana Hablemos de cine com a exclamação "o cinema paraguaio existe!", mas o filme foi logo censurado pelos próximos vinte anos de ditadura. Somente filmes como Cerro Corá, produzido sob auspícios estatais, tiveram chance de chegar à audiência.

Mesmo com a queda da ditadura, no fim dos anos 1980, e a passagem para um regime democrático, Encina afirma que o quadro anterior - política, social, econômica e cinematograficamente falando - não se modificou expressivamente. A diretora queria falar, então, do silêncio como inexistência de um cinema que exprimisse, como ela diz, a identidade paraguaia, mas também do silêncio como característica de um povo. Com uma história marcada por guerras e pela sucessão de regimes totalitários, seus conterrâneos estariam presos a um passado glorioso, sempre esperando que os dias melhores retornassem ${ }^{5}$. É como se as ditaduras e as guerras não tivessem acabado.

A ideia inicial do filme - contar a ausência do filho de Cândida e Ramón, e como essa perda deveria ser dolorosa para os pais -, afigurou-se então, para Encina, como algo mais

\footnotetext{
3 No original: "La comunidad cultural fue hostigada y dividida: muchos vivieron la soledad del exilio o permanecieron asfixiados en el país. Algunos artistas produjeron trabajos notables en estas condiciones - los escritos de Augusto Roa Bastos son ejemplares a este respecto- pero en cine el trabajo fue escaso y aislado".

4 No original: “'tierra sin hombres y hombres sin tierra', según palabras de Roa Bastos".

Eva Romero (2012) aponta a Guerra da Tríplice Aliança e a Ditadura Stroessner como os dois momentos que mais deixaram marcas no que ela chama de paraguayidad, marcada pela fixação no passado. Apesar de toda a violência cometida nestas ocasiões, as pessoas a neutralizariam em uma nostalgia com relação aos considerados tempos melhores, em que havia menos crimes e que a comida era mais barata do que nos dias de hoje. No original: "The legacy of the Triple Alliance War and the Stroessner regime involve pessimism about the future and turning a blind eye toward the past violence of the regime, neutralizing it in a nostalgic reminiscence of better times when there was less crime and more cheap food" (ROMERO, 2012, p.317).
} 
abrangente: ela percebeu que estava abordando a história do Paraguai dos últimos 200 anos. Em suas palavras, o filme “(...) tinha uma locação totalmente circular, com dois personagens que entravam e saíam constantemente de um buraco negro... de uma boca de lobo. Me dei conta, um dia, de que contava a história da continuidade da continuidade" (ENCINA, 2008, p.341) $)^{6}$.

Embora concordemos que os aspectos repetitivos presentes no filme evidenciem um “não avançar", preferimos pensar na ideia de uma suspensão, estado decorrente de um trauma experimentado por um casal de velhos que não está localizado antes, mas à margem da história. Suspender o tempo para que não sigam adiante mutilados. Afinal, ainda que as repetições pareçam designar a naturalização de uma trajetória, algo como um destino, como parece sugerir a diretora, Hamaca nos indica um possível marco a originar a causa desse estado. A entrada e a saída de Cândida e Ramón, toda vez que o ambiente da rede retorna à cena, os assuntos, os pássaros, os latidos, os planos do céu nublado, nos parecem antes exprimir as consequências de algo que acometeu os personagens - no caso, a ida do filho para a guerra e a indeterminação de sua morte, do que uma história fadada à repetição. Desenvolveremos a ideia melhor a seguir, através do conceito de "pausa".

\section{Pausa: ver e ouvir}

Andrea Molfetta (2011), analisando filmes latino-americanos contemporâneos que ela considera atualizações de road movies $^{7}$, coloca a construção temporal como decisiva para evidenciar a inoperância dos personagens perante suas realidades, o que, por sua vez, acarreta a sensação de que nada acontece nos filmes. Os tempos mortos, tempos de inação, são

\footnotetext{
6 No original: “(...) tenía ya una locación totalmente circular, con dos personajes que entraban y salían constantemente de un agujero negro... de una boca de lobo. Me di cuenta, un día, de que contaba la historia de la continuidad de la continuidad".

Em seu texto "Naturaleza y personaje en el cine latino-americano del nuevo siglo", Molfetta (2011) analisa os filmes Qué tan lejos (Tania Hermida, 2006), equatoriano, Cómo pasan las horas (Inés de Oliveira Cézar, 2004), argentino, Cinema, aspirinas e urubus (Marcelo Gomes, 2005), brasileiro, $O$ ano em que meus pais saíram de férias (Cao Hamburguer, 2006), uma coprodução entre Brasil e Argentina, e Lo más bonito y mis mejores años (Miguel Boulocq, 2005), boliviano.
} 
trazidos pela pesquisadora sob a denominação de "pausa", buscada em Gerard Genette no livro Figures III (1972). Segundo o autor, que vem da teoria literária, o termo se refere a uma operação que impede a reflexividade entre a história e o texto, reflexividade no sentido de que um ecoa no outro. É uma operação que busca deixar o leitor na presença do puro discurso, da palavra enquanto procedimento, sem expandir essa condição para outros sentidos.

Molfetta (2011) relaciona esses momentos em que nada acontece, colocando o espectador como que imerso na contemplação da imagem e do som, ou seja, imerso na pausa, às situações óticas e sonoras puras apresentadas por Deleuze (2007). Conforme o autor francês, essas situações seriam decorrentes de um trauma coletivo provocado pela Segunda Guerra Mundial, que o cinema moderno ofereceu como uma destituição da crença dos sujeitos no mundo, resultando na impossibilidade de construir relatos sobre o que se passou, e também de agir na realidade em que se encontravam. Situações óticas e sonoras puras, portanto, como um estágio anterior à elaboração do pensamento, como encontro com a realidade mais literal. Porém, no caso latino-americano, o conceito evidencia situações distintas.

Nos filmes analisados por Molfetta, a situação traumática atravessa um âmbito mais individual. Os personagens, empurrados por suas histórias de opressão, de marginalidade, de submissão, engatam viagens ou, de alguma forma, deslocamentos sem uma busca clara, sem rumo. E são nesses trânsitos, quando os personagens se relacionam com a natureza, que a autora identifica a presença da pausa. A ausência de motivação e de engajamento dos sujeitos em seus deslocamentos configura os tempos mortos que podemos associar à pausa, os tempos do "nada se passar", quando ficamos diante da pura imagem e do puro som que as cenas nos oferecem.

Embora nos distanciemos da concepção de naturalização da história decorrente do contato com a natureza, conforme elaborado pela autora, consideramos ser a pausa, associada aos longos planos desdramatizados e aos tempos mortos, uma interessante figura para pensarmos a relação de Hamaca Paraguaya com o trauma da perda. Acrescentaríamos aqui também a repetição das falas e gestos, bem como as vozes que vagam por tempos e espaços distintos, além da quase inação dos corpos, como elementos que endossam a ideia de pausa, o que, por sua vez, permite a associação do filme ao estado melancólico. 
A duração das imagens de Hamaca nos retira da situação confortável de espectadores acostumados a ver somente aquilo que interessa ao desenvolvimento de uma narrativa, baseada nas ações encadeadas dos personagens, com os quais nos identificamos, torcendo pelo desvelamento de mistérios; ao contrário, nos faz questionar aquilo que vemos. Como diz Deleuze (2007) a partir de Bergson:

(...) nós não percebemos a coisa ou a imagem inteira, percebemos sempre menos, percebemos apenas o que estamos interessados em perceber, ou melhor, o que temos interesse em perceber, devido a nossos interesses econômicos, nossas crenças ideológicas, nossas exigências psicológicas. Portanto, comumente, percebemos apenas clichês. Mas, se nossos esquemas sensórios-motores se bloqueiam ou quebram, então pode aparecer outro tipo de imagem: uma imagem ótico-sonora pura, a imagem inteira e sem metáfora, que faz surgir a coisa em si mesma, literalmente, em seu excesso de horror ou de beleza, em seu caráter radical ou injustificável, pois ela não tem mais de ser 'justificada', como bem ou como mal... (DELEUZE, 2007, p.31).

É devido à pausa que paramos para ouvir o guarani, que dedicamos um tempo de nossas vidas para saber da guerra e sentir junto com os pais de Máximo a dor da perda de um filho, afinal, como espectadores, estamos mergulhados na duração concreta dessa espera. Como afirma Romero (2012), os longos planos e os tempos lentos do filme podem ser vistos como uma maneira de confrontar e "(...) interromper uma economia narrativa congruente ao capitalismo" (ROMERO, 2012 p.313) ${ }^{8}$. Podemos dizer que a pausa permite, dessa forma, interromper a linearidade das histórias oficiais e voltar o olhar para aquilo que elas atropelam e para o que delas resta, aqueles que vivem em outras temporalidades. "Pausa" que resiste para que suas memórias se tornem nostalgia. "Pausa" para olhar para aquilo que ainda permanece. "Pausa": antes melancolia que trabalho realizado de luto.

\footnotetext{
8 No original: "Hamaca's long takes and slower tempo can be read as an attempt at harnessing the potential of slowness to disrupt a narrative economy that is congruent with capitalism".
} DOI: $10.17851 / 2179-8478.0 .9 .80-102$ 


\section{Luto, história e resto}

Na última cena do filme, Cândida e Ramón recolhem sua rede e se dirigem ao fundo do quadro, já imersos no escuro do dia que termina. A lamparina carregada pelo pai clareia fracamente o caminho, como um ponto de luz nas sombras, como um vagalume. Falas sobre a escuridão e sobre o esquecimento dão o tom da última cena do filme. De Hamaca Paraguaya, resta o barulho da chuva. Alguma esperança é sugerida pela presença, ainda que apenas na banda sonora, da água tão almejada pelo casal de velhos. Ela caiu, enfim, mas eles não estavam mais lá. Se provaram ou não do alívio trazido pela tormenta, não saberemos. Os dois se foram para não serem apanhados pelas trevas da noite; trevas que, no entanto, tomarão conta de suas memórias. Como responde Cândida ao alerta de Ramón sobre o fato de estarem esquecendo a rede: "Esqueceremos diversas coisas mais tarde".

O esquecimento para eles soa acalentador, como se esquecendo a ausência de Máximo fosse possível seguir em frente, desligar-se desse tempo outro em que estão presos e pensar em uma vida sem o filho. Assim eles se vão, com as juras de amparo que um oferece ao outro. "Não vamos chorar", "a única coisa que faz chorar é a morte”, "não estamos sozinhos, não deixaremos um de nós sozinho", "estamos felizes assim”, dizem Cândida e Ramón, expressões que soam mais como alternativas às quais eles tentam se agarrar, palavras que querem tornar verdade. Os diálogos da última cena são assim um pouco tortuosos, ora retomam a dor da perda, envolvida nas reclamações acerca do calor e dos latidos da cadela, ora abrem um caminho em meio às sombras, como sinais de um luto em vias de ser elaborado.

O trabalho de luto pressupõe a possibilidade de realizar um relato sobre o passado, nos diz Idelber Avelar (2003). Narrar a perda sofrida, conseguir falar sobre ela como perda, ou seja, como algo que se foi, é resultado de operações substitutivas e metafóricas que permitem à libido investir em outros objetos. Embora Cândida e Ramón por vezes comentem a ausência de Máximo como a confirmação de sua morte e reflitam sobre sua impotência diante dela, predomina a resistência em aceitá-la.

Considerado uma reação normal a uma situação de perda, o luto é uma etapa praticamente inevitável para aquele que a sofreu e que busca conviver com a ausência de DOI: 10.17851/2179-8478.0.9.80-102 
maneira saudável. Aquele luto que não se realiza e mantém o sujeito no tempo da perda é considerado patológico e indica que algo não vai bem. $\mathrm{O}$ desprendimento é necessário para seguir adiante. Mas, e quando seguir adiante não é o desejado? Tomamos aqui uma perspectiva mais ampla, que nos leva a indagar a quem interessa e a que serve a realização dos trabalhos de luto dos mortos produzidos ao longo da história.

\footnotetext{
A parálisis no luto indicaria então uma ruptura da metáfora: o sujeito em luto percebe a unicidade e a singularidade do objeto perdido como prova irrefutável de sua resistência a qualquer substituição, isto é, a qualquer transação metafórica. Concebemos aqui tal momento de resistência à metáfora não simplesmente como uma fase transitória e ao fim superável do trabalho de luto, mas como o próprio lugar a partir do qual o luto se converte numa prática afirmativa com consequências políticas fundamentais (AVELAR, 2003, p.236).
}

Discutindo as operações do luto nas sociedades submetidas aos ditames do capital, Avelar (2003) explica que “(...) o mercado maneja uma memória que se quer sempre metafórica, na qual o que importa é por definição substituir, relocar, estabelecer uma relação com um lugar a ser ocupado, nunca com uma contiguidade interrompida" (AVELAR, 2003, p.13). Toda informação e todo produto devem ser passíveis de substituição, afinal, o consumo exige sempre que se adquira o novo. O passado, matéria de memória acabada, total, sem arestas, é ele também tornado objeto de consumo, para isso é preciso colocá-lo em seu lugar, no passado, numa operação substitutiva sem resíduos.

No entanto, esse processo metafórico do mercado não é levado a cabo de forma plena. "Ao produzir o novo e descartar o velho, o mercado também exige restituição. A mercadoria anacrônica, desfeita, reciclada ou museificada encontra sua sobrevida enquanto ruína" (AVELAR, 2003, p.14), fragmento que ganha vida naquilo tornado obsoleto pelo mercado. E os resíduos produzidos por esse processo de adquirir o novo e descartar o velho não podem ser de todo silenciados e apagados, afinal, conforme o autor, tais restos apontam para o passado, exigindo restituição pelo que se perdeu. Trazendo a discussão para o contexto específico do pós-ditatorial da América Latina, Avelar (2006) contrapõe a vontade de narrar o testemunho da barbárie à necessidade da política hegemônica de promover a diluição da DOI: $10.17851 / 2179-8478.0 .9 .80-102$ 
memória.

O autor está interessado na produção literária que procura, de alguma forma, elaborar os longos anos vividos sob regime totalitário, como os argentinos Ricardo Piglia e Tununa Mercado. Estes escritores, na leitura de Avelar (2003), estariam na contramão das políticas que buscam promover o esquecimento dos anos de repressão. Caminhando no intempestivo, as narrativas, tão diferentes entre si, buscam meios para impedir que a ferida se feche, mesmo reconhecendo que sempre resta algo de inenarrável nestas experiências, algo que nenhuma palavra pode traduzir.

A literatura pós-ditatorial testemunharia, então, esta vontade de reminiscência, chamando a atenção do presente a tudo o que não se realizou no passado, recordando ao presente sua condição de produto de uma catástrofe anterior, do passado entendido como catástrofe. A literatura pós-ditatorial teria assim uma vocação intempestiva no sentido nietzchiano, "atuando contra o nosso tempo e portanto sobre nosso tempo, e, espera-se, em benefício de um tempo vindouro". No mesmo mercado que submete o passado à imediatez do presente, a literatura enlutada buscará esses fragmentos e ruínas - rastros da operação substitutiva do mercado - que podem ativar a irrupção intempestiva do passado no presente: irrupção que recorda à atualidade seu fundamento, sua ancoragem no inatual (AVELAR, 2003, p.238-239).

Embora a lógica do mercado, no seu ímpeto metaforizante, possa ser associada ao processo em direção ao chamado luto bem-sucedido, há nele um traço paradoxal. Conforme o autor, mais que se realizar, é próprio ao processo do luto "resistir ao seu próprio logro". Diferente da tomada de lugar do velho pelo novo necessária à dinâmica do consumo, o sujeito do luto se apega ao passado. É como se, de alguma forma, o sujeito do luto soubesse que a sua tarefa é irrealizável. Nesse sentido, “(...) se nunca haverá incorporação do objeto perdido, se não haverá idealização do outro sem deixar atrás um resíduo inassimilável, ficará sempre no trabalho de luto uma dimensão irredutível a qualquer operação metafórica" (AVELAR, 2003, p.240). Resistência do luto em ser reduzido a uma simples lógica de mercado. Nenhuma operação ou tentativa de substituição se dá sem deixar restos pelo caminho. Nenhum processo de esquecimento pode ser tão absoluto que impeça a retomada das lembranças daqueles que 
ainda podem contá-las, mesmo que seja através de fragmentos.

A literatura enlutada trabalhada por Avelar (2003) compartilha um momento do imediato pós-ditatorial. Ainda que tateando linguagens possíveis para narrar o terrível e o incompreensível, nessas obras é possível apontar, de alguma forma, o que se perdeu. As obras lançadas durante as décadas de 1980 e 1990 trazem à tona os restos dos períodos de censura e repressão, contribuindo para montar o quebra-cabeças de sombras que não entram nos relatos oficiais.

Há que se fazer a ressalva quanto às diferenças de suportes, linguagens e contextos entre a literatura discutida pelo autor e o filme (todos latino-americanos, mas produzidos em países com trajetórias distintas). Ainda assim, acreditamos que todos eles lidam com formas de elaborar ou de dar a ver traumas históricos na América Latina pelo viés do luto e da melancolia. O filme de 2006 foi lançado dezessete anos após a derrubada da ditadura no Paraguai ${ }^{9}$, mas ele delega à Guerra do Chaco, ocorrida na década de 1930, a responsabilidade pela dor de Cândida e Ramón. Mesmo assim, não se trata de uma responsabilização clara, uma vez que as informações sobre a guerra não nos são oferecidas senão por fragmentos.

Romero (2012), bem como Marina Moguillansky (2012) e Ana Inés Couchonnal Cancio (2010), ao comentarem eventos traumáticos da história do Paraguai, apontam a Guerra da Tríplice Aliança como o mais devastador e aquele que teria influenciado mais fortemente a maneira do povo se ver e se portar, ou a constituição de uma identidade. Moguillansky (2012) comenta que o país teve que passar décadas se recuperando econômica e politicamente do massacre que a guerra causara; ganhar a do Chaco, então, representaria uma forma de retomar o otimismo no país. O Paraguai, em considerável desvantagem estratégica e no número de soldados com relação à Bolívia, realmente venceu.

E, ainda assim, não é a guerra o que importa em Hamaca. A guerra levou Máximo e é só na ausência do filho que ela se faz presente na vida dos pais. O filme é sobre aqueles que ficam, aqueles que não foram contados, não têm voz ou poder de decisão. A guerra não é trazida como um evento passado, com uma lógica interna descolada do presente. A guerra não

9 Lembremos que, para autores como Eva Romero (2012), a transição da ditadura para a democracia nunca ocorreu de fato, já que as mesmas pessoas que estavam antes no poder continuam a controlar o país. 
elaborada, constantemente retomada, não passou. Ela e a ausência do filho de Cândida e Ramón são latência vivida no presente.

O filme se volta para o extracampo de um evento que a tudo atropela, sem piedade, deixando nos campos de batalha corpos sem nome, sem família, sem significado. Estes pereceram, mas e aqueles que ficaram para trás? Histórias interrompidas pela engrenagem da história que não pode parar. Se o que resta é aquilo que permanece inalcançável, inenarrável, o filme encontra-se precisamente entre os restos. Trazer à tona uma guerra já terminada há tantas décadas para sugerir, talvez, que ela não está de todo terminada. Há algo que permanece ${ }^{10}$. O avançar rumo ao progresso não permite pausas e pelo caminho vão ficando aqueles relatos, testemunhos, narrações, versões e memórias tão poderosos quanto frágeis perante as narrativas oficiais, afinal, caminhando com Benjamin (2012), a história é sempre a história dos vencedores.

Segundo Jeanne Marie Gagnebin (2011), “(...) Benjamin tenta pensar uma 'tradição’ dos oprimidos que não repousaria sobre o nivelamento da continuidade, mas sobre os saltos, o surgimento (...), a interrupção e o descontínuo: 'o continuum da história é o dos opressores" (GAGNEBIN, 2011, p.99). Essa perspectiva de olhar a história a partir da lacuna e do

$10 \quad$ Eva Romero (2012) inicia seu artigo narrando uma disputa entre campesinos e o governo em junho de 2012. Em sua discussão, a autora focaliza o lugar do campesino na sociedade paraguaia e o evento narrado serve para reforçar a ainda marginalizada posição que ocupam. “(...) Uma violenta disputa por terra resultou no impeachment do Presidente Fernando Lugo. Setenta pessoas foram mortas em troca de tiros entre policiais e trabalhadores sem terra (...). A polícia foi enviada para despejar cerca de 150 trabalhadores da terra, uma reserva florestal de propriedade de Blas Riquelme, um político de oposição ao Presidente Fernando Lugo. Advogados dos campesinos sem-terra argumentaram que a terra foi erroneamente adquirida pelo Estado por Riquelme durante a ditadura Stroessner e deveria ter feito parte do programa de reforma agrária. Lugo venceu a eleição presidencial em 2008 em parte devido ao programa de reforma agrária que beneficiaria 87000 famílias de agricultores paraguaios, embora essa guerra nunca tenha sido levada adiante. Na cobertura midiática que cobriu os tiroteios e em seguida o impeachment, a figura do campesino foi retratada como desde a vítima mais marginalizada do Estado à criminosos fora da lei” (ROMERO, 2012, p.311). No original: “A violent land dispute takes place resulting in the impeachment of President Fernando Lugo. Seventeen people are killed in gun battles between the police and landless farmers (or hired guns. At the time of this writing there is insufficient evidence to determine who, exactly, started the shooting.) The police had been sent in to evict about 150 farmers from the land, a forest reserve owned by Blas Riquelme, a politician opposed to President Fernando Lugo. Advocates for the campesinos sin tierra argued that the land was wrongfully acquired from the state by Riquelme during the Stroessner dictatorship and should have been part of a land reform program. Lugo won the presidential election in 2008 in part on a promise of agrarian reform that would benefit 87,000 Paraguayan farm families, although this was never delivered. In the media coverage that followed the gun battle and ensuing impeachment, the campesino figure was depicted in ways that ran the gamut from the most disenfranchised victim of the State to the most violent and lawless of criminals"

DOI: $10.17851 / 2179-8478.0 .9 .80-102$ 
fragmento vai de encontro ao chamado historicismo, que busca encaixar os fatos em uma cadeia de causalidade "chata e tola” (Gagnebin, 2011). Na concepção de Benjamin, é preciso ruir essa cadeia, pois “(...) somente a tentativa de parar o tempo pode permitir a uma outra história vir à tona, a uma esperança de ser resguardada em vez de soçobrar na aceleração imposta pela produção capitalista" (idem, p.98). A interrupção é uma forma de desconstruir a ordem das palavras e das coisas, de barrar esse continuum.

A perspectiva benjaminiana, portanto, caminha em direção à desnaturalização do conhecimento histórico. Promovendo a quebra no fluxo das palavras, é possível perceber que elas não são fruto de um processo orgânico e universal, são antes resultado de escolhas arbitrárias a serviço de interesses.

(...) a história habitual é, de fato, a "comemoração" das façanhas dos vencedores, ela é a "apologia" que tende a "recobrir os momentos revolucionários do curso da história". A essa narrativa cumulativa e complacente ele [Benjamin] opõe, nos dois fragmentos, a necessidade de ater-se a tudo o que poderia interromper essa aparente coerência: "A ela [isto é, à habitual representação da história ou à apologia] escapam os lugares nos quais a transmissão se interrompe, e com isso, suas asperezas e suas arestas que oferecem uma escora àquele que quer ir além dela”. Parafraseando essas linhas, podemos afirmar que aquele que quer ir além dessa tradição dos vencedores (...) deve saber agarrar-se a essas asperezas (...), a essas arestas (...) que lhe oferecem tantas escoras ou pontos de apoio (...) na sua luta contra o fluxo nivelador da história oficial que, justamente, deixa escapar esses "lugares nos quais a tradição/transmissão se interrompe" (GAGNEBIN, 2011, p.100).

Parar e notar rastros, os restos deixados pelo fluxo, é uma das formas de se operar a interrupção. Para isso, é necessário o esforço de pensar a existência à luz de perdas. Conforme Jaime Ginzburg (2012), aquele que busca ler a história a contrapelo, para usar os termos de Benjamin, precisa não apenas perceber a realidade imediata, mas “(...) entender cada objeto como uma potência latente do que não foi dito, por ter sido silenciado ou por ter havido esquecimento" (GINZBURG, 2012, p.110). O rastro tem uma existência ambígua, é a presença de uma ausência, e, por isso, dentro da lógica fugaz do mercado, que a tudo precisa 
substituir, ele é uma chave de conhecimento. Afinal, considerando o rastro em relação a uma trajetória, ele ganha significação histórica.

\begin{abstract}
Uma catástrofe, como a Primeira Guerra Mundial, produz traumas. Um genocídio, ao dizimar uma população, apaga a sua memória. A reflexão sobre o rastro representa um confronto sério e qualificado com as políticas de esquecimento. A partir de elementos residuais, é possível construir uma história voltada contra os agentes de destruição. Aquilo que a guerra e o genocídio eliminam pode encontrar voz em um movimento irruptivo, que frature a linearidade do tempo, em favor da evocação de um tempo libertário. A categoria do rastro inspira a reconstrução constante do ato de narrar, conferindo ao detalhe, ao resto, um papel constitutivo do passado. Contra os discursos totalizantes do autoritarismo, irrompe a linguagem dissociativa, que permite realizar saltos no processo de conhecimento (GINZBURG, 2012, p.115).
\end{abstract}

Rastro como chave para compreender o trauma. Rastro que resiste ao luto. Rastro como aquilo que não quer se deixar esquecer. Os personagens campesinos distantes da câmera, o guarani, a natureza, as pistas de uma guerra ao longe... São como rastros. Na fugacidade do tempo e das imagens, o filme oferece uma pausa, suspende o fluxo, nos faz olhar para Cândida e Ramón e ouvi-los em sua dor. Hamaca Paraguaya não chama a atenção para um grande acontecimento, não oferece uma narrativa épica sobre a saga paraguaia contra os bolivianos no Chaco. Ele oferece o resto, através de uma perspectiva ainda mais marginal: a afetiva, representada principalmente pela dor de Cândida, a mãe. O resto do resto.

Conforme Cancio (2010), o resultado da guerra da Tríplice Aliança marca a fundação de uma chamada paraguayidad, que foi associada ao feminino e, por isso, ao inferior. A guerra custou ao país grande parte de sua população masculina e, de acordo com Romero (2012), como foram as mulheres as encarregadas pela reconstrução, atribui-se a esse momento de destruição da nação e do núcleo familiar a responsabilidade por muitos dos problemas sociais e econômicos enfrentados ainda hoje. E o filme opta por abordar uma vitória masculina sob uma perspectiva que se pode dizer feminina, dos afetos, de uma mãe que viu partir o filho. Ainda que Ramón, o pai, se alie mais ao posicionamento de aceitação e valorização da defesa da pátria, ele também sofre do mesmo descontentamento de Cândida, 
ele também gostaria de ter notícias do filho e de tê-lo de volta, e a tênue diferença de posicionamento frente à ausência, entre um e outro, vai se perdendo, até que se agarram um no outro e na necessidade de mandar a morte para longe.

Cândida e Ramón estão sob as trevas do trauma. Hamaca Paraguaya possibilita que vislumbremos, em meio à produção audiovisual latino-americana ou mesmo mundial, resíduos que nos permitem desconstruir e reconstruir a história, ou ainda, que nos permitem indagar o atual. Afinal, Cândida e Ramón ainda lamentam a ausência do filho. Há pais que choram seus filhos e há mortos que não foram velados e enterrados. E eles habitam o presente como fantasmas. Os mortos que não foram enterrados não podem ser objeto de luto, afirma Avelar (2003). Para levar o luto a cabo, é preciso restituí-los ao seu lugar de mortos e liberálos da condição de fantasmas, ou seja, transformá-los em memória. No entanto, conforme o autor, essa liberação não é percebida senão como uma traição para o sobrevivente da hecatombe, afinal, funciona como um segundo assassinato. "A transformação da repetição compulsiva em recordação termina por não diferenciar-se, aos olhos do enlutado, de sua submersão nas águas barrentas do esquecimento" (p.255-256).

Não se quer para Máximo um reconhecimento de glória como um soldado que morreu na guerra. Negar a morte do filho, negar o furo na camisa que indica o tiro fatal, é não permitir que ele seja esquecido, para assim poder ser retomado na versão dos pais. Esse é o grande desafio do sujeito em estado de melancolia, narrar aquilo que sabe que jamais conseguirá dizer. Eis o paradoxo. Narrar é uma traição para com os mortos, no sentido de que nenhuma palavra faz jus a eles, enquanto, por outro lado, "renunciar a contar e a transmitir, mesmo por falta de palavras ou por excesso de dor, significaria, de uma certa maneira e sem querê-lo, pactuar com a ignomínia" (GAGNEBIN, 2011, p.109). De acordo com Jeanne Marie Gagnebin (2011), a tarefa da história humana é narrar o que não pode ser contado, ser fiel ao passado e a seus mortos, principalmente quando não sabemos seus nomes e seu sentido.

Identificamos no filme uma situação em que não foram encontradas ainda as ferramentas necessárias para fazê-lo. Se narrar implica, então, tanto um segundo assassinato dos mortos quanto o respeito à sua memória, Hamaca Paraguaya não narra. Ele dá a ver, antes, o estado de melancolia, que não encadeia as palavras e as coisas, pois não é capaz de 
nomear a perda. Ao enfatizar e reconhecer o inominável, o filme se aproxima do que chamaríamos de um cinema contemporâneo. E, quando falamos em contemporâneo, não estamos pensando simplesmente na produção cinematográfica dos anos 2000 para cá, marco aproximado da inauguração do novísimo cine latinoamericano que apresentamos anteriormente. Estamos falando desse cinema que nos permite, de alguma forma, perceber as sombras.

Contemporâneo é o intempestivo. Para Giogio Agamben (2009), contemporâneo é aquele que, descolado de seu tempo, está profundamente a ele ligado, pois só assim é possível percebê-lo. Em um tempo em que tudo são imagens, tudo são luzes, contemporâneo é aquele que consegue ver a obscuridade, é aquele capaz de, como afirma o autor, escrever nas trevas do presente. Poderíamos dizer que o contemporâneo também é o melancólico que, percebendo o entorno à luz de perdas, está e não está em seu tempo. Assim, se falamos em Hamaca Paraguaya como um exemplar do cinema contemporâneo, é porque ele nos conduz a enxergar não no escuro, mas o escuro - do dia que começa, do dia que termina. No entanto, talvez como uma outra forma de conceber a relação com a história, o filme não dá a ver a obscuridade para que nela possamos reunir pontos de luz que constituam novas versões, novos relatos, senão para reconhecê-la enquanto tal, inapreensível, inalcançável, inominável: escuro.

\section{Considerações finais}

Hamaca Paraguaya costuma ser relacionado a uma série de filmes lançados na América Latina do início dos anos 2000 em diante. Os silêncios, os tempos-mortos e a banalidade do cotidiano de personagens simples são apontados como alguns dos elementos que constituem escolhas frequentes neste cinema recente. $\mathrm{O}$ autor equatoriano Galo Alfredo Torres (2011), incluindo o longa paraguaio no corpus de filmes de cineastas jovens e 
independentes lançados a partir dos anos 2000 que analisa ${ }^{11}$, chega a nomear essa leva de "neorrealismo cotidiano".

Estes filmes, também reunidos pelo autor sob a categoria de novíssimo cine latinoamericano são por vezes contrapostos ao cinema de meados do século XX, que deu expressão e reconhecimento para a produção cinematográfica da América Latina. Compara-se e contrasta-se, à forte crítica política e social e ao apelo militante contra as injustiças do imperialismo, o comezinho e o "menor" dos filmes recentes. O autor usa o temo "cotidiano" para designar as ações, predominantes nos filmes, simples, triviais, circunscritas ao dia a dia dos personagens, sem grande importância no desenvolvimento narrativo.

A pesquisadora argentina Andrea Molfetta (2011), também interessada nos traços comuns a este cinema contemporâneo, destaca como opção frequente a de apresentação de sujeitos sem rumo, cujas histórias não avançam e que estão sempre olhando para trás, como que ligados a algo que foi perdido, enlutados. Isso, de acordo com a autora, associado às percepções de Torres (2011), dentre outras implicações, denotaria a perda de uma dimensão de reflexão histórica, resistência e luta políticas. Para ela, as obras evidenciariam a impossibilidade deste cinema de narrar a partir de um ponto de vista pós-colonial, sendo os caminhos incertos e a passividade dos personagens frente ao que os acomete fatores que indicariam a diluição de um ímpeto transformador de seu contexto.

Como discutimos ao longo do trabalho, embora o comezinho possa ser encontrado em Hamaca e as ações aparentemente não motivem o desenvolvimento narrativo, não consideramos que isso se dá sem reservas, como apenas uma forma de mostrar a vida e "nada mais". Não se trata do "comezinho" ou do simples cotidiano. As ações que realizam Cândida e Ramón sofrem o impacto de algo que os acometeu no passado e que os retira do seu cotidiano integrado. Cândida lava roupas e Ramón corta cana na lavoura, por exemplo, sem a presença do filho; este núcleo familiar incompleto, como se sugere através dos relatos, não $11 \quad$ No livro Héroes menores: neorrealismo cotidiano y cine latinoamericano contemporâneo de entresiglos, o autor destina atenção mais detida às obras Historias Minimas (Carlos Sorin, 2002), Whisky (Juan Pablo Rabella y Pablo Stoll, 2004), En la cama (Matías Bize, 2005), Temporada de patos (Fernando Eimbcke, 2004), Suíte Habana (Fernando Pérez, 2003) e Los Muertos (Lisandro Alonso, 2004), além do nosso filme de interesse específico, Hamaca Paraguaya.

DOI: $10.17851 / 2179-8478 \cdot 0.9 .80-102$ 
corresponde à "normalidade" da família. Os pais trabalham, mas em um estado entre a perda do filho e a sua aceitação. Em Hamaca, as consequências da perda nos conduzem à sugestão de um filme sob a ação do trauma. Esse estado, provocado pela guerra em Hamaca, não nos parece ignorar ou encerrar o potencial político da escritura fílmica, tão caro ao cinema latino do século passado, mas sim experimentá-lo sob novas formas.

Enquanto os Cinemas Novos da América Latina dos anos 1960 e 1970 colocavam-se frente à história com um ímpeto explicativo, denunciativo e crítico das mazelas sociais, da corrupção política, do imperialismo capitalista, Hamaca Paraguaya apresenta o menor, o silêncio, a dor. Não queremos, com isso, concluir que o cinema latino-americano tenha perdido inteiramente a ambição crítica, mas que, nos melhores casos, seu trabalho político se dá sob novas formas. Aquele cinema estava preocupado com o lugar do Terceiro Mundo em um contexto de Guerra Fria e de separação do globo em três, sendo seu discurso mais totalizante e sua crítica mais certeira, pois se sabia para onde apontar as armas. Em um filme como Hamaca, não se trata mais de clamar a união de todos os povos oprimidos do continente, senão de olhar para estes que estão distantes, dentro dos próprios limites nacionais.

\section{Referências bibliográficas}

AGAMBEN, Giorgio. O que é o Contemporâneo? E outros ensaios. Chapecó: Argos, 2009.

ARNADE, Charles W. Prólogo. In: ZOOK JR., David H. La conducción de la Guerra del Chaco. Asunción: Editorial Lito, 1962.

AVELAR, Idelber. Alegorias da derrota. Belo Horizonte: Editora UFMG, 2003.

BENJAMIN, Walter. Sobre o conceito de história. In: . $O$ anjo da história. Belo Horizonte: Autêntica Editora, 2012. Pp.7-20. 
CANCIO, Ana Inês Couchonnal. Lecturas paraguayas posibles. Hamaca Paraguaya como espacio de reflexión de la realidad nacional. In: Observatorio Latinoamericano 2 - Dossier Paraguay. Buenos Aires, mayo 2010. P.33-36.

DELEUZE, Gilles. A imagem-tempo. Eloisa de Araújo Ribeiro (trad.). São Paulo: Brasiliense, 2007.

DELEUZE, Gilles. A imagem-movimento. Stella Senra (trad.). São Paulo: Brasiliense, 1985.

ENCINA, Paz. Arrastrando la tormenta. In: Russo, E. (comp). Hacer cine. Producción audiovisual en América Latina. Buenos Aires: Paidós, 2008.

ENCINA, Paz. Paz Encina escribe sobre "Hamaca paraguaya". 2007. Disponível em: < http://www.abcguionistas.com/noticias/articulos/paz-encina-escribe-sobre-hamacaparaguaya.html>. Acesso em abril de 2014.

FIGLEY, Charles (org). Trauma and its wake - volume 1. Brunner/Mazel Psychosocial stress series, 1985.

FREUD, Sigmund. Luto e melancolia. São Paulo: Cosac Naify, 2011.

GAGNEBIN, Jeanne Marie. História e Cesura. In: . História e Narração em Walter Benjamin. São Paulo: Perspectiva, 2011. Pp. 93-114.

GINZBURG, Jaime. A interpretação do rastro em Walter Benjamin. In: GINZBURG, Jaime; SEDLMAYER, Sabrina (orgs). Walter Benjamin: rastro, aura e história. Belo Horizonte: Editora UFMG, 2012. Pp.107-132.

KING, John. El carrete magico: Una historia del cine latinoamericano. Bogotá: Tercer DOI: $10.17851 / 2179-8478.0 .9 .80-102$ 
Mundo Editores, 1994.

KRISTEVA, Julia. Sol Negro - Depressão e melancolia. Carlota Gomes (trad.). Rio de Janeiro: Rocco, 1989.

MOGUILLANSKY, Marina. Confrontando pasados. Las guerras históricas en las coproducciones del Mercosur. III Congreso Internacional de la Asociación Argentina de Estudios de Cine y Audiovisual. 2012.

MOLFETTA, Andrea. Naturaleza y personaje en el cine Latinoamericano del nuevo siglo. In: ZAVALA, Lauro (org.). Reflexiones teóricas sobre cine contemporâneo. Toluca de Lerdo, Gobierno del Estado de México, 2011.

PARTIDA, Gabriel Domínguez. El rumbo del cine hispanoamericano. El eterno caminar de Lake Tahoe. El ojo que piensa. Revista de cine iberoamericano, año 4, núm. 7. EneroJunio, 2013.

ROMERO, Eva Karene. Hamaca Paraguaya (2006): Temporal Resistance and Its Impossibility. Arizona Journal of Hispanic Cultural Studies, Volume 16, 2012, pp.311-330.

TORRES, Galo Alfredo. Héroes Menores - neorrealismo cotidiano y cine latinoamericano contemporâneo de entresiglos. Quito: Universidad de Cuenca, 2011.

TORRES, Galo Alfredo. Neorrealismo cotidiano. Contar lo que passa después del clímax del realismo sucio al cine del no passa nada. 2012. Disponível em: $<$ http://www.kilometro8ymedio.net/?p=368>. Acesso em: jan. 2012.

ZOKNER, Cecilia Teixeira de Oliveira. Céspedes e Roa Bastos, duas visões da guerra do Chaco: unidade. Revista Letras, Curitiba, v.21/22. 1974. 
ZOOK JR., David H. La conducción de la Guerra del Chaco.Asunción: Editorial Lito, 1962. 